\title{
Anaphylactic reactions to polyethylene glycol-containing bowel cleansing preparations after Moderna COVID-19 vaccination
}

Shortly after emergency use authorization of COVID-19 mRNA vaccines was given, the first reports of anaphylactic reactions emerged. While the causative agent is still a matter of debate, allergy to the excipient polyethylene glycol (PEG) is a possible explanation [1]. PEG is a hydrophilic polymer with variable molecular weight and also the main constituent of many bowel cleansing agents used prior to colonoscopy. Anaphylaxis to PEG-containing bowel cleansing preparations is exceedingly rare, with an estimated average of four cases per year in the USA [2].

Within a timespan of 3 weeks, three patients cancelled appointments for colonoscopies at our endoscopy department owing to anaphylactic reactions to the PEG-containing bowel cleansing agent, which they had tolerated well for previous colonoscopies. All patients had received vaccination with the COVID-19 mRNA vaccine made by Moderna 12-18 days before these events. Radioallergosorbent tests (RASTs) did not detect specific anti-PEG IgE in any of the three patients. Two patients opted for inpatient allergy testing at our hospital. Both had positive skin reactions after intradermal testing with serial dilutions of the Moderna COVID-19 vaccine and one patient also had a positive skin reaction to PEG 6000. Interestingly, indurated plaques developed on the Moderna vaccine injection sites and lasted for 2 days. Detailed descriptions of symptoms and clinical findings are provided in Table 1s (see online-only Supplementary material).

The onset of a new PEG allergy shortly after COVID-19 vaccination makes a causal relationship likely. Possible mechanisms include a "classical" type 1 hypersensitivity by vaccine-triggered anti-PEG IgE antibodies and an IgG/IgM-mediated hypersensitivity reaction called "comple- ment activation-related pseudoallergy" [1]. PEG-specific anti-IgE was not detectable in any of the three patients, but this does not rule out an IgE-mediated type 1 allergy owing to the sensitivity issues of RAST in general [3]. Typical skin reactions shortly after intradermal injection of the vaccine itself (two patients) and PEG 6000 (one patient) may support a possible type 1 allergy. However, the formation of indurated cutaneous infiltrations after intradermal application of the vaccine could also point to elements of a T cell-mediated delayed-type hypersensitivity.

Surprisingly, the patient who declined allergy testing received a second dose of the Moderna COVID-19 vaccine without an allergic reaction. However, dose seems to be a critical factor for a clinical response in patients with PEG allergy: incremental oral challenge of a patient with known PEG allergy resulted in a systemic response only after receiving very high doses, levels usually only reached during bowel preparation for colonoscopy [4]. Another recent case series noted individual thresholds for dose and/or molecular weight in patients with anaphylaxis after PEG exposure [5].

Vaccine-induced de novo formation or boosting of anti-PEG IgM/lgG causing a complement activation-related pseudoallergy is an alternative explanation for the reactions seen in these three patients, as this entity is usually dose-dependent. To the best of our knowledge, this is the first publication of a possible vaccine-triggered PEG (pseudo)allergy. Healthcare professionals should be aware of the possibility of a newly developed PEG allergy after COVID-19 vaccination. Endoscopists particularly may see these cases as patients typically ingest high doses of PEG during colonoscopy bowel preparation.

\section{Competing interests}

The authors declare that they have no conflict of interest.

The authors

Maximilian Schreiner ${ }^{1} \stackrel{\oplus}{ }$, Christian Zobel ${ }^{1}$, Ulrich Baumgarten ${ }^{1}$, Tina Uhlmann ${ }^{2}$, Staffan Vandersee ${ }^{2}$

1 Department of Internal Medicine, Bundeswehr Hospital, Berlin, Germany

2 Department of Dermatology, Bundeswehr Hospital, Berlin, Germany

\section{Corresponding author}

\section{Maximilian Schreiner, MD \\ Bundeswehrkrankenhaus Berlin, Klinik I (Innere Medizin), Scharnhorststr. 13, 10115 Berlin, Germany MaximilianSchreiner@bundeswehr.org}

\section{Acknowledgments}

We would like to thank T. Braasch, T. Steingräber, and S. Rolle for bringing these cases to our attention. 


\section{References}

[1] Risma KA, Edwards KM, Hummell DS et al. Potential mechanisms of anaphylaxis to COVID-19 mRNA vaccines. J Allergy Clin Immunol 2021; 147: 2075-2082.e2

[2] Stone CAJr., Liu Y, Relling MV et al. Immediate hypersensitivity to polyethylene glycols and polysorbates: more common than we have recognized. J Allergy Clin Immunol Pract 2019; 7: 1533-1540 e1538
[3] Ansotegui I], Melioli G, Canonica GW et al. IgE allergy diagnostics and other relevant tests in allergy, a World Allergy Organization position paper. World Allergy Organ J 2020; 13: 100080

[4] Sohy C, Vandenplas O, Sibille Y. Usefulness of oral macrogol challenge in anaphylaxis after intra-articular injection of corticosteroid preparation. Allergy 2008; 63: 478-479

[5] Sellaturay P, Nasser S, Ewan P. Polyethylene glycol-induced systemic allergic reactions (anaphylaxis). J Allergy Clin Immunol Pract 2021; 9: 670-675

Bibliography

Endoscopy 2022; 54: 517-518

DOI 10.1055/a-1640-9686

ISSN 0013-726X

published online 28.10.2021

(c) 2021. The Author(s).
This is an open access article published by Thieme under the terms of the Creative Commons Attribution-NonDerivativeNonCommercial License, permitting copying and reproduction so long as the original work is given appropriate credit. Contents may not be used for commercial purposes, or adapted, remixed, transformed or built upon. (https://creativecommons.org/licenses/by-nc-nd/4.0/)

Georg Thieme Verlag KG, Rüdigerstraße 14,

70469 Stuttgart, Germany

\section{(ㄷ)(1)}

$\circledast$ Supplementary material

Supplementary material is available under https://doi.org/10.1055/a-1640-9686 